\title{
Design and Realization of City Tourism Route Intelligent Programming System
}

\author{
Zhou Xiao ${ }^{a}$, Zhang Yiming ${ }^{\mathrm{b}}$, Chen Li ${ }^{\mathrm{c}}$, Lin Haizhao ${ }^{\mathrm{d}}$, Zhu Shuai \\ Information Engineering University, No.62 Kexue Avenue, High-tech Zone, Zhengzhou, Henan \\ province, China \\ azhou_laoge@163.com, bzbgzgy@163.com, ${ }^{\mathrm{a}} \mathrm{clhj} 20130813 @ 163 . c o m$, \\ dinhaizhao1102@163.com, ${ }^{\mathrm{e}}$ maple0081@aliyun.com
}

Keywords: city tourism; neural net; tourism route; intelligent programming; system development

\begin{abstract}
Travelers choosing tourism route subjectively is usually not optimal. Set neural net algorithm as data model, city tourism route intelligent planning system is designed and developed. The sampling method is used to select urban scenic spot, and intelligent programming algorithm is set up. The function and structure of the system are designed. Through system developing and function example analyzing, system's main function and auxiliary function are studied. Function test and user experience show that this system has good operation, while planned tourism route can meet the needs of most tourist group and obtain the maximum tourist motive benefits.
\end{abstract}

\section{Introduction}

For tourists, in what way they can visit all the selected scenic spots in the shortest time and get maximum tourist motive benefits, is the most concern. Nowadays, tourism geographic information system seldom contains intelligent tourism route planning service. Before visiting the city scenic spots, tourists get scenic spot and route information usually by surfing Internet, purchasing books, consulting online, etc., and then make self-decision ${ }^{[1,2]}$. Usually, tourist decision is not optimal. It is difficult to get the maximum tourist motive benefits. Therefore, programming tourism route by using intelligent method, providing decision support for tourists, is the trend of tourism geographic information system ${ }^{[3]}$. This paper develops tourism route intelligent programming system, which can help tourists make decision and get maximum motive benefits.

\section{City Scenic Spots Sampling}

Intelligent tourism route programming uses tourism demand as motive resource. Each tourist has his interests in certain scenic spots ${ }^{[4]}$. Set Zhengzhou urban scenic spots as data resource. Collect $n$ scenic spots as superset $Q$. Classify scenic spots to 4 groups, labeled as $Q_{u}, 0<u \leq 4$, including $Q_{1}$ park \& green field, $Q_{2}$ play yard, $Q_{3}$ venue and $Q_{4}$ shopping and leisure. Each subset contains element scenic spots respectively, labeled as $H_{v}, 0<v \leq \max v_{Q_{u}}$, shown in Formula 1. 


$$
\sum_{u=1}^{4} \max v_{Q_{u}}=n
$$

Sampling scenic spots, and $n=21$. According to attributive character, classify these scenic spots and get Zhengzhou scenic spot structure Fig.1 and scenic spot distribution Fig.2.

$Q_{1}=\left\{Q_{1} H_{1}\right.$ Botanical garden; $Q_{1} H_{2}$ West lake park; $Q_{1} H_{3}$ Renmin park; $Q_{1} H_{4}$ Zijingshan park; $Q_{1} H_{5}$ Lvcheng square; $Q_{1} H_{6}$ Zhengzhou zoo; $Q_{1} H_{7}$ Bishagang park; $Q_{1} H_{8}$ Forest park $\}$;

$Q_{2}=\left\{Q_{2} H_{1}\right.$ East District happy world; $Q_{2} H_{2}$ The water world; $Q_{2} H_{3}$ Century joy garden $\}$;

$Q_{3}=\left\{Q_{3} H_{1}\right.$ Province museum; $Q_{3} H_{2}$ Aquarium; $Q_{3} H_{3}$ Erqi memorial; $Q_{3} H_{4}$ Municipal museum; $Q_{3} H_{5}$ Municipal science and technology museum $\}$;

$Q_{4}=\left\{Q_{4} H_{1} \mathrm{CC}\right.$ mall; $Q_{4} H_{2}$ Department store building; $Q_{4} H_{3}$ Daxue road Uanda; $Q_{4} H_{4}$ Qin Ling road Uanda; $Q_{4} H_{5}$ Pedestrian street $\}$

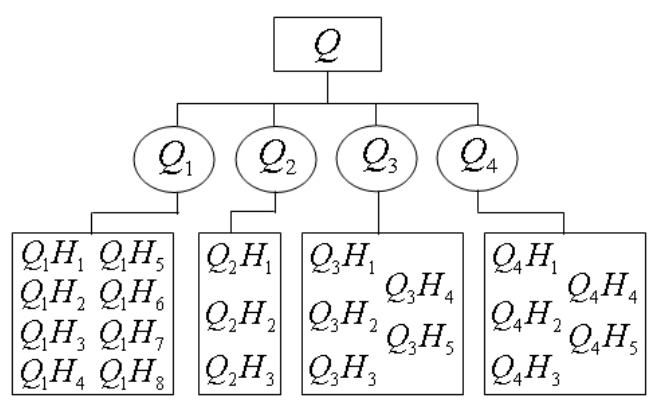

Fig.1 Structure of Zhengzhou city scenic spots

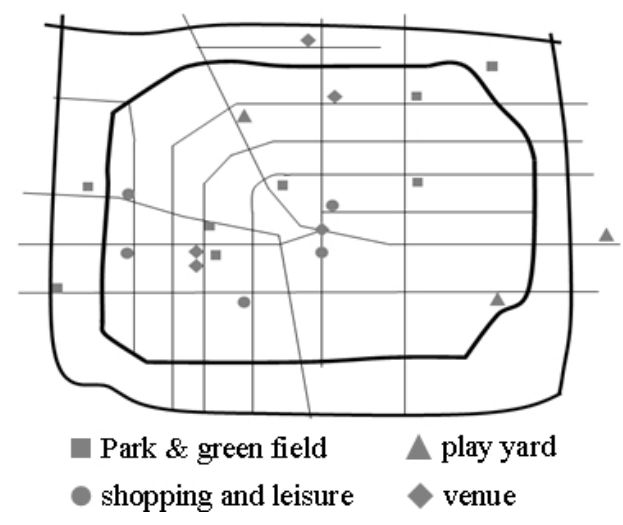

Fig.2 Zhengzhou Scenic spots distribution

\section{Data Modeling and System Design}

\subsection{Data Modeling.}

Define scenic spot set as $T$, in which there are $k$ selected scenic spots $T_{1}, \ldots, T_{k}$. Usually, tourist visits scenic spots in one-way sequence. There exists $r$ impact factors influencing tourist motive such as interval distance, scenic spot star level, hotel quantity, restaurant quantity, convenience store and bus route quantity, etc. Factors have their own fluctuating value to promote or inhibit themselves. Set factor set as $U$, fluctuating value set as $\eta$, here are factors $U_{1}, U_{2}, \ldots, U_{r}$ and fluctuating values $\eta_{1}, \eta_{2}, \ldots, \eta_{r}$. According to neural net iteration model, motive iteration output value is $I$, as formula 2 shows.

$$
I_{i}=\sum_{0<i \leq k} U_{r} I_{i-1}+\eta_{r}
$$

Neural net iteration provides the condition of intelligent programming. Tourist motive value is iterated by motive factors. $A_{k}^{k}$ tourism routes are determined by $k$ scenic spots. Set 
up $(2) \times\left(A_{k}^{k} / 2\right)$ dimension matrix $W$ to store $A_{k}^{k}$ motive output value. Descend sort tourist motive output value in matrix $W$, and draw maximum value $\max I$ which is related to the optimal route.

\subsection{System Design.}

Here is the content of system design.

\subsubsection{System Function and Structure Design.}

In function, system realizes intelligent tourism route programming and ancillary function. Tourists rely on their own time and arrangement to select scenic spot subclass and choose certain scenic spots $^{[5]}$. System intelligently calculates maximum output value max $I$ to provide optimal route and suboptimal routes to make decision support for tourists. For the needed service in the tour process such as weather, tourism index, bus and subway information, railway and flight information, etc., tourists can look up information by themselves. In structure, system uses GIS two level design mode $\mathrm{C} / \mathrm{S}$. The main structure contains two layers, one is the subject of route programming function, and the other is auxiliary function. Each layer contains related subclass modes with different functions.

\subsubsection{Data Model Design.}

Geographic information data is various and plentiful. For the convenience of management and application, multi-classification databases are designed to store data. System contains three databases according to function needs, they are (1) Scenic spot information database and sub-database, (2) Traffic information database and sub-database, (3) Scenic spot buffer service information database and sub-database. They respectively store scenic spot attribute data and spatial data, bus and subway station information within scenic spot buffer, interval distance, taxi fee, traffic jam index, traffic light and crossroad quantity and traffic accident probability, etc., service attribute data and spatial data within scenic spot buffer. Data model is shown in Fig. 4.

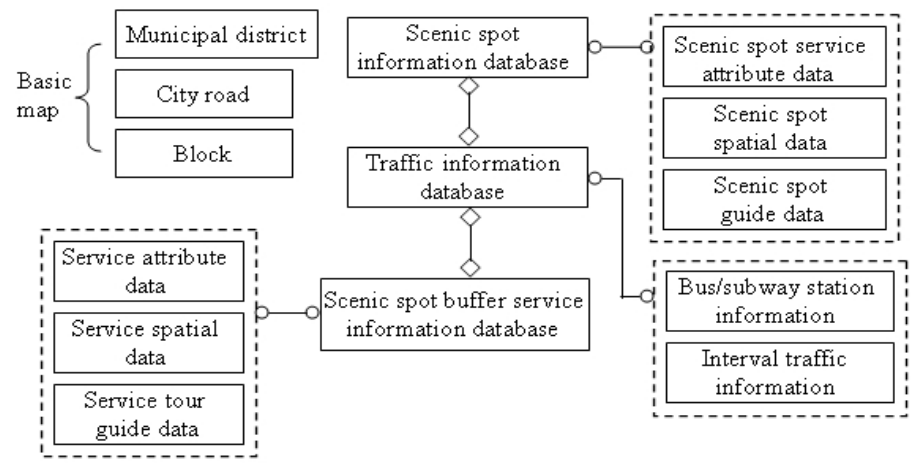

Fig. 4 System data model design

\section{System Developing and Function Example}

\subsection{Developing Tool and Environment.}

Develop system on the basis of designing system function and structure. Visual Studio 2015 platform, Access database and MapInfo map design software are used to develop system. System developing faces attribute data and spatial data and designs many interfaces to transfer data stored in Access database. 


\subsection{Hardware Environment.}

System developing uses one server DELL PowerEdge 12G R720 with 12 G computer memory, equipped with large capacity hard disk $500 \mathrm{G}$. Output device is Canon iP2780 printer.

\subsection{Software Environment.}

Operating system is Windows 7. Programming environment is Visual Studio 2015. Database is Access database. Basic map charting tool is MapInfo map design software.

\subsection{System Function Example.}

System realizes intelligent city tourism route programming. It automatically calculates motive output value and intelligently chooses the optimal route. Meanwhile, it analyzes suboptimal routes and provides decision support for tourists. System function and related testing include the main function test and auxiliary function test.

\subsection{System Main Function Example.}

Tourists utilize the intelligent tourism route programming function to choose $Q_{1} H_{3}$ Renmin park, $Q_{3} H_{3}$ Erqi memorial and $Q_{3} H_{5}$ municipal science and technology museum. It automatically programs six tourism routes and visually displays as Fig.5 shows. According to intelligent calculation, the sequence $Q_{1} H_{3} \rightarrow Q_{3} H_{3} \rightarrow Q_{3} H_{5}$ can finally get the maximum tourism motive benefits. The other five suboptimal routes as well as the optimal route are all used to make decision support and the information is displayed in the system.

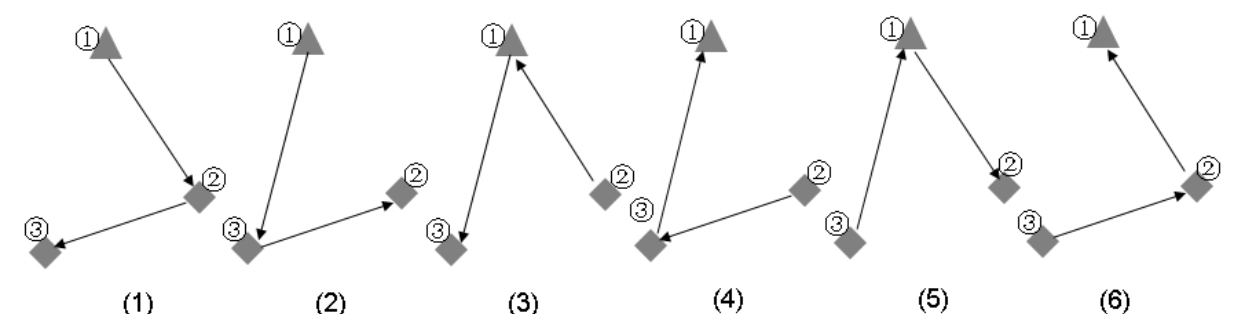

Fig.5 Tourism route programmed by system

\subsection{System Auxiliary Function Example.}

In addition to the main function, system realizes auxiliary functions, including the following auxiliary functions.

(1) Zhengzhou tourism information inquery

Tourists use "integrated information" function to know about Zhengzhou geographic location, administrative region, history and culture, natural scenery and cultural characteristics, etc. and special local product information.

(2) Classic attractions information inquery

Tourists use "Scenic spot information" function to choose scenic spots. All the selected information is displayed in visualization list box. Meanwhile, reset, delete and newly increase, etc. can be operated. Select any scenic spot and tourist can look up tourism information.

(3) Outdoor information inquery 
Tourists can choose municipal district weather information, time frame weather, tourism index, etc. according to the needs. They can find information of bus and subway station, route, hotel, restaurant, hospital, convenience store and financial and postal service, etc. For the convenience of tourists traveling, system also provides railway and flight information inquery service.

(4) Thematic map service function

On the basis of decision support, tourists choose certain route. If map service is needed, system "Map setting" and "Map printing" can be used to print maps with tourism route charted on the map.

(5) Feedback function

Tourists can use "feedback" function to enter information input interface and type in feedback information for the developer. It is convenient for the developer to modify and improve the system.

\section{Summary}

Based on neural net model, this paper uses GIS hierarchy structure to develop city tourism route intelligent programming system. This system can provide intelligent tourism route programming function and related auxiliary function. The system has tough practicability, especially when tourists firstly come to an unfamiliar city, the system provides great convenience for them. Function test and user experience show that this system has good operation performance. Planned tourist routes meet the needs of most tourist group and can obtain maximum motive benefits.

\section{Acknowledgements}

Here I should appreciate my research group. They all did a good job in the research work and we worked together to complete the paper. Thanks to all of our members' help.

\section{References}

[1] ZHAO X M, SUN Q X, DING Y. Passenger choice behavior for regional rail transit under express/local operation with overtaking. Journal of Transportation Systems Engineering and Information Technology, 2016,16(5), p.104-109.

[2] WANG C Y, QU H L. Tourist motive,destination image and tourism expectation. Tourism Tribune,2013,28(6), p.26-34.

[3] LONG X Q, WANG J J, ZHOU B. Travelers dynamic decision making based on decision field theory. Journal of Transportation Systems Engineering and Information Technology, 2016,16(1), p.12-18.

[4] Nicolau J L,Ma's F J. The influence of distance and prices on the choice of tourist destinations:the moderating role of motivations. Tourism Management, 2006, 27, p.982-996.

[5] LI X J, CUI S S, ZHANG K. Neural net method of best tourism route choice. Transportation and Computer, 2006,24(5), p.103-106. 